
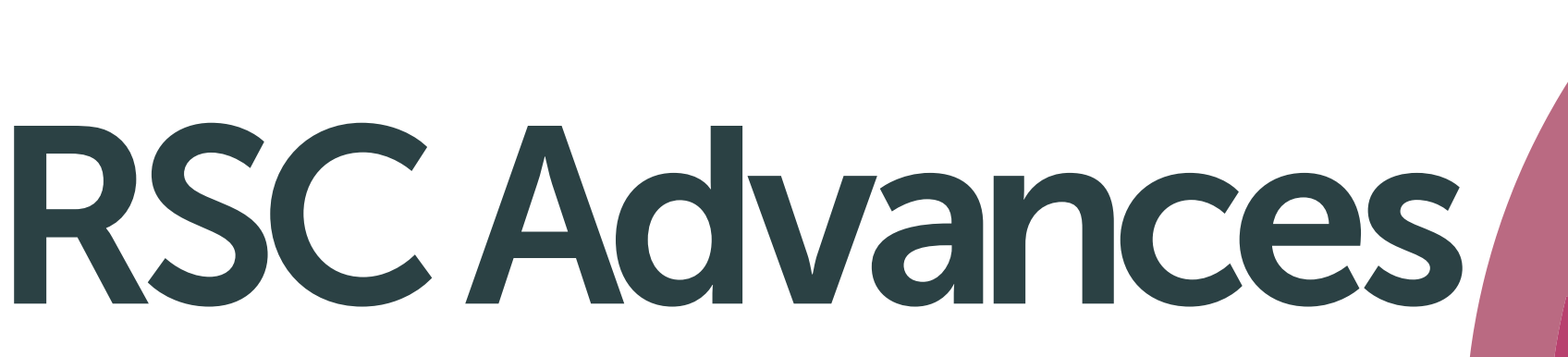

Volume1 Number1 Jan 2013 $\mid$ Pages 1-100

\section{RSC Advances}

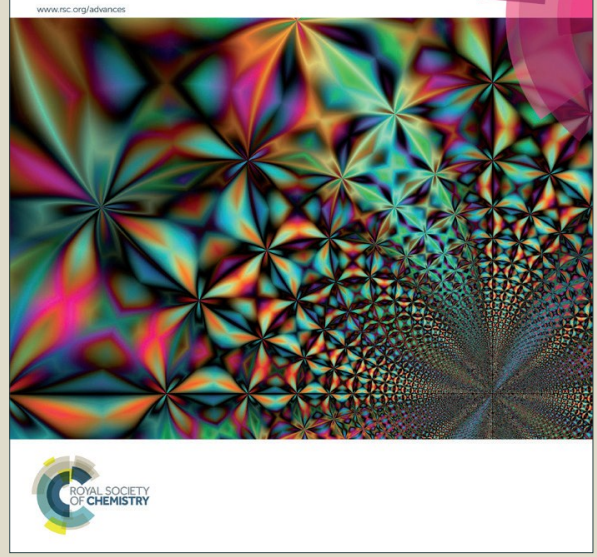

This is an Accepted Manuscript, which has been through the Royal Society of Chemistry peer review process and has been accepted for publication.

Accepted Manuscripts are published online shortly after acceptance, before technical editing, formatting and proof reading. Using this free service, authors can make their results available to the community, in citable form, before we publish the edited article. This Accepted Manuscript will be replaced by the edited, formatted and paginated article as soon as this is available.

You can find more information about Accepted Manuscripts in the Information for Authors.

Please note that technical editing may introduce minor changes to the text and/or graphics, which may alter content. The journal's standard Terms \& Conditions and the Ethical guidelines still apply. In no event shall the Royal Society of Chemistry be held responsible for any errors or omissions in this Accepted Manuscript or any consequences arising from the use of any information it contains. 


\title{
Supramolecular Assemblies Constructed from Inverted Cucurbit[7]uril and Lanthanide Cations: Synthesis, structure and sorption properties.
}

\author{
Qing Li, ${ }^{\text {a }}$ Sheng-Chao Qiu, ${ }^{\text {a }}$ Yun-Qian Zhang, ${ }^{\text {a }}$ Sai-Feng Xue, ${ }^{\text {a }}$ Zhu Tao, ${ }^{\text {a Timothy J. Prior, }}$ \\ Carl Redshaw, ${ }^{b^{*}}$ Qian-Jiang Zhu, ${ }^{* a}$ Xin Xiao**a \\ ${ }^{a}$ Key Laboratory of Macrocyclic and Supramolecular Chemistry of Guizhou Province, Guizhou \\ University, Guiyang 550025, China \\ ${ }^{\mathrm{b}}$ Department of Chemistry, University of Hull, Hull HU6 7RX, U.K.
}

Corresponding authors: E-mail: gyhxxiaoxin@163.com (X. Xiao); zqjgzu@126.com (Q. J. Zhu); c.redshaw@hull.ac.uk Tel: +86-851-83620906 (X. Xiao); Fax:+86-851-83620906 (X. Xiao)

\begin{abstract}
The interaction of a series of lanthanide cations $\left(\mathrm{Ln}^{3+}\right)$ with inverted cucurbit[7]uril $(i \mathrm{Q}[7])$ in the presence of $\left[\mathrm{ZnCl}_{4}\right]^{2-}$ anions as a structure-directing agent have been investigated. Single-crystal X-ray diffraction analysis has revealed that the $\left[\mathrm{ZnCl}_{4}\right]^{2-}$ anions surround the $i \mathrm{Q}[7]$ molecules via outer surface interactions of $i \mathrm{Q}[7]$. This results in the formation of honeycomb-like frameworks, and ultimately linear supramolecular chains of $i \mathrm{Q}[7]$ in which $\mathrm{Ln}^{3+}$ cations occupy voids within the framework. Moreover, these $i \mathrm{Q}[7] / \mathrm{Ln}^{3+}$-based supramolecular assemblies exhibit excellent thermal stability as well as permanent porosity, and in one case screening
\end{abstract}


revealed high $\mathrm{CH}_{3} \mathrm{OH}$ uptake capacity compared with other porous organic materials assembled solely through hydrogen bonding under ambient conditions.

Keywords: inverted cucurbit[7]uril; lanthanide cations; $\left[\mathrm{ZnCl}_{4}\right]^{2-}$ anion; coordination; supramolecular assemblies 


\section{Introduction}

Inverted cucurbit $[n]$ urils $(i \mathrm{Q}[n] \mathrm{s}, n=6,7)$ are characterized by the displacement of two methine hydrogen atoms of a glycoluril unit within their cavities, and were first reported by Isaacs and Kim in $2005 .{ }^{[1]}$ Subsequently, it was demonstrated that $i \mathrm{Q}[n] \mathrm{s}$ can convert into $\mathrm{Q}[n] \mathrm{s}$ following heating in concentrated $\mathrm{HCl} .{ }^{[2]}$ Given that $i \mathrm{Q}[7]$ has a slightly smaller cavity than that of Q[7], it can display some different host-guest properties. For example, $i \mathrm{Q}[7]$ binds aromatic guests tighter than linear aliphatic guests. ${ }^{[1]}$ Also, the Ka value of $i \mathrm{Q}[7]$ for aromatic guests is somewhat higher than that for voluminous guests such as adamantine, which is in sharp contrast to the behaviour of $\mathrm{Q}[7]$, which displays much higher affinity for adamantine 3 than for aromatic guests. $^{[1]}$ However, difficulties associated with the separation of $i \mathrm{Q}[n] \mathrm{s}$ had hindered the investigation of their chemistry. Indeed, only four studies and one patent involving $i \mathrm{Q}[n] \mathrm{s}$ have been reported to date. ${ }^{[2-6]}$ However, recently we found that $i \mathrm{Q}[6]$ or $i \mathrm{Q}[7]$ can be easily isolated from $\mathrm{Q}[6]$ or a water-soluble mixture of $\mathrm{Q}[n] \mathrm{s}$ by column chromatography on Dowex resin. ${ }^{[7-9]}$ The subtle difference in the outer surface interactions of $\mathrm{Q}[n]$ and $i \mathrm{Q}[n]$ results in a significant difference in their chromatographic behaviour, and their resultant separation has further facilitated the development of $i \mathrm{Q}[n]$ chemistry. ${ }^{[7]}$

Interestingly, polychloride transition metallated anions $\left(\left[\mathrm{M}_{\mathrm{d}-b l o c k} \mathrm{Cl}_{\mathrm{x}}\right]^{\mathrm{n}-}\right)$, in particular, $\left[\mathrm{CdCl}_{4}\right]^{2-}$ and $\left[\mathrm{ZnCl}_{4}\right]^{2-}$ have proven effective structure directing agents in the construction of $\mathrm{Q}[n] /$ Metal coordination complexes and supramolecular 
coordination polymers. ${ }^{[9-12]}$ The interaction of electronegative $\left[\mathrm{M}_{\mathrm{d}-b l o c k} \mathrm{Cl}_{\mathrm{x}}\right]^{\mathrm{n}-}$ anions and the electropositive outer surface of $\mathrm{Q}[n] \mathrm{s}$ generally leads to the formation of $\left[\mathrm{M}_{\mathrm{d}-b l o c k} \mathrm{Cl}_{\mathrm{x}}\right]^{\mathrm{n}-}$-based honeycomb-like frameworks (the so-called honeycomb effect of $\left.\left[\mathrm{M}_{\mathrm{d}-\mathrm{block}} \mathrm{Cl}_{\mathrm{x}}\right]^{\mathrm{n}-}\right)$, resulting in $\mathrm{Q}[n]-$-metal-based coordination polymers, which occupy the cells of the frameworks. ${ }^{[7,20]}$ Our recent studies have shown that both $i \mathrm{Q}[6]$ and $i \mathrm{Q}[7]$ can coordinate with alkaline-earth metal ions ${ }^{[9]}$ in the presence of the $\left[\mathrm{ZnCl}_{4}\right]^{2-}$ anion as a structure-directing agent ${ }^{[10-12]}$ resulting in the formation of different supramolecular assemblies. More recently, investigation of the interactions of $i \mathrm{Q}[6]$ with lanthanide cations $\left(\mathrm{Ln}^{3+}\right)$ in the presence of the $\left[\mathrm{ZnCl}_{4}\right]^{2-}$ anion revealed that they give rise to different products and isomorphous groups based on increasing atomic number. The interaction of $i \mathrm{Q}[6]$ with $\mathrm{La}^{3+}$ and $\mathrm{Ce}^{3+}$ immediately yielded precipitates, and likewise crystalline solids were obtained with $\operatorname{Pr}^{3+}$ and $\mathrm{Nd}^{3+}$. No solids resulted from the coordination of $i \mathrm{Q}[6]$ with $\mathrm{Sm}^{3+}$ and $\mathrm{Eu}^{3+}$, whereas crystalline solids were obtained from its coordination with the remaining heavy $\mathrm{Ln}^{3+}, \mathrm{Ln}=$ Gd-Lu; such observations demonstrated the recognition of lanthanide cations by $i \mathrm{Q}[6] .{ }^{[8]}$ Moreover, different $\mathrm{Q}[n] \mathrm{s}$ exhibit different selectivity for $\mathrm{Ln}^{3+}$ and the interaction or coordination of $\mathrm{Q}[n] \mathrm{s}$ with $\mathrm{Ln}^{3+}$ is strongly affected by the synthetic conditions employed. ${ }^{[21]}$ Previous studies have proven that $\mathrm{Q}[n]$-based supramolecular assemblies could be used as hydrogelators, ${ }^{[13]}$ for the capture of gases such as acetylene $^{[14]}$ or carbon dioxide, ${ }^{[15]}$ and that both $\mathrm{Q}[6]$ - and $\mathrm{Q}[8]$-based porous materials show anisotropic proton conductivity. ${ }^{[16]}$ The combination of $\mathrm{Q}[n]$-based coordination complexes and $\mathrm{Q}[n]$-based supramolecular assemblies could open up 
limitless possibilities.

In the present work, the coordination chemistry of $i \mathrm{Q}[7]$ (Figure 1) towards lanthanide cations $\left(\mathrm{Ln}^{3+}\right)$, in the presence of the $\left[\mathrm{ZnCl}_{4}\right]^{2-}$ anion as a structure-directing agent, in aqueous $\mathrm{HCl}$ has been investigated. Single-crystal X-ray diffraction analysis revealed that $\left[\mathrm{ZnCl}_{4}\right]^{2-}$ anions surround $i \mathrm{Q}[7]$ molecules via outer surface interactions and form honeycomb-like frameworks, and ultimately result in the formation of linear supramolecular chains of $i \mathrm{Q}[7]$ with $\mathrm{Ln}^{3+}$ cations, the latter occupying the voids of the framework. Moreover, the linear $i \mathrm{Q}[7] / \mathrm{Ln}^{3+}$-based supramolecular chains arrange into novel supramolecular assemblies, which in one case was shown to exhibit high $\mathrm{CH}_{3} \mathrm{OH}$ uptake capacity when compared with other porous organic materials assembled solely through hydrogen bonding under ambient conditions $^{[17-19]}$.

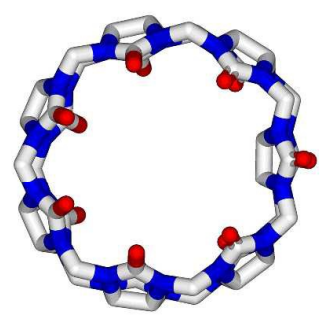

(a)

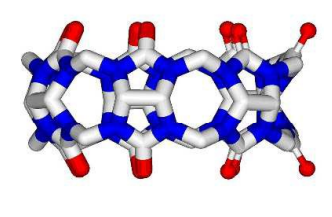

(b)

Fig. 1. Structure of the inverted cucurbit[7] uril as viewed from the top (left) and from the side (right).

\section{Results and Discussion}

\section{Description of the crystal structures.}

Figure 2 shows the crystal structure of compound $\mathbf{1}$ obtained from the 
$i \mathrm{Q}[7]-\mathrm{Eu}^{3+}-\mathrm{ZnCl}_{2}-\mathrm{HCl}$ system. A supramolecular assembly is evident (Figure 2a) in which the $\left[\mathrm{ZnCl}_{4}\right]^{2-}$ anions are arranged into a honeycomb-like framework (Figure $2 \mathrm{~b}$ ), and each 'hollow' within the honeycomb has one $i \mathrm{Q}[7]-\mathrm{Eu}^{3+}$-based "bee pupa" (Figure 2a, 2c). Each $i \mathrm{Q}[7]$ molecule in the "pupa" is surrounded by seven $\left[\mathrm{ZnCl}_{4}\right]^{2-}$ anions via the outer surface interactions of $i \mathrm{Q}[7]$, including dipole-dipole interactions between $\mathrm{Cl}$ from $\left[\mathrm{ZnCl}_{4}\right]^{2-}$ anions and methine or methylene (black dashed lines) of the $i \mathrm{Q}[7]$ molecule (Figure 2d). Distances between chloride and methine or methylene carbons fall within the range 3.406-3.445 A. Additional hydrogen bonding interactions between the inverted carbonyl oxygens and the methylene groups on the outer surface of the $i \mathrm{Q}[7]$ molecules (red dashed lines) from two neighbouring linear polymers (Figure 2e) are also evident. The distances between the inverted carbonyl oxygens (O11) and the hydrogens (H23B and H24A) are in the range 2.543-2.645 $\AA$. Unlike the unsubstituted $\mathrm{Q}[7] / \mathrm{Ln}^{3+}$-based supramolecular coordination polymers where neighbouring Q[7] molecules are linked by direct coordination with $\mathrm{Ln}^{3+}$ cations ${ }^{[8,13]}$ here each $i \mathrm{Q}[7]-\mathrm{Eu}^{3+}$-based supramolecular "pupa" is constructed of $1: 1$ $i \mathrm{Q}[7] / \mathrm{Eu}^{3+}$ complexes. Furthermore, a $\mathrm{Eu}^{3+}$ cation $(\mathrm{Eu} 1)$ of a $i \mathrm{Q}[7] / \mathrm{Eu}^{3+}$ complex coordinates at one portal of the $i \mathrm{Q}[7]$ molecule, and interacts with the portal of a neighbouring $i \mathrm{Q}[7] / \mathrm{Eu}^{3+}$ complex via hydrogen bonding (Figure $2 \mathrm{f}$ ). Each $\mathrm{Eu}^{3+}$ cation (Eu1) coordinates with eight oxygen atoms, two carbonyl oxygens $(\mathrm{O} 1, \mathrm{O} 2)$ from a $i \mathrm{Q}[7]$ molecule, and six water molecules $(\mathrm{O} 1 \mathrm{~W}, \mathrm{O} 2 \mathrm{~W}, \mathrm{O} 3 \mathrm{~W}, \mathrm{O} 4 \mathrm{~W}, \mathrm{O} 5 \mathrm{~W}, \mathrm{O} 6 \mathrm{~W})$, which interact with the portal carbonyl oxygens of a neighbouring $i \mathrm{Q}[7]$ molecule. Some additional interactions exist between the two neighbouring $i \mathrm{Q}[7]$ molecules, 
including: 1) hydrogen bonding between the five coordinated water molecules $(\mathrm{O} 2 \mathrm{~W}$, $\mathrm{O} 3 \mathrm{~W}, \mathrm{O} 4 \mathrm{~W}, \mathrm{O} 5 \mathrm{~W}, \mathrm{O} 6 \mathrm{~W})$ and the portal carbonyl oxygens $(\mathrm{O} 14, \mathrm{O} 8, \mathrm{O} 9, \mathrm{O} 10, \mathrm{O} 12)$ (2.836-2.887 $\AA$ in blue dashed lines, Figure 2f); the hydrogen bonding distances are in the range 2.657-2.809 $\AA$. 2) hydrogen bonding interactions between a portal carbonyl oxygen of the $i \mathrm{Q}[7]$ molecule and a methylene group from the neighboring $i \mathrm{Q}[7]$ molecule with hydrogen bonding distances in the range 2.867-3.010 $\AA$ (red dashed lines, Figure 2f). Thus, a combination of all these interactions resulted in the formation of the $i \mathrm{Q}[7]-\mathrm{Eu}^{3+}-\left[\mathrm{ZnCl}_{4}\right]^{2-}$ supramolecular coordination assembly.

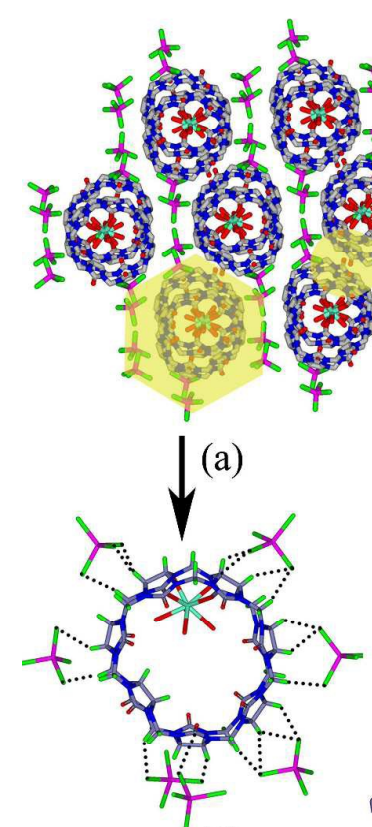

(d)

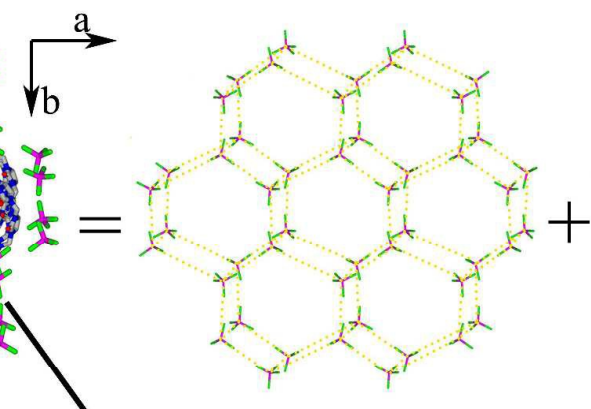

(b)

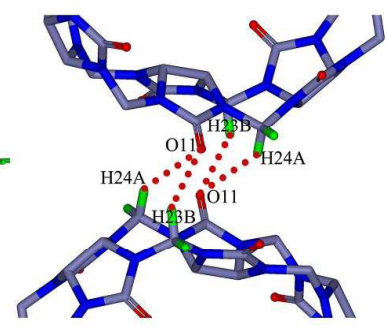

(e)

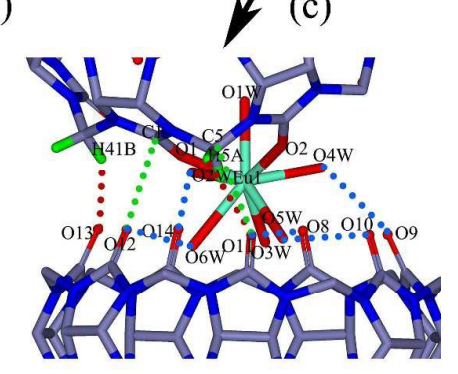

(f)

Fig. 2. X-ray crystal structure of compound 1: (a) overall view of the supramolecular assembly constructed of $i \mathrm{Q}[7]-\mathrm{Eu}^{3+}$ complexes and $\left[\mathrm{ZnCl}_{4}\right]^{2-}$ anions along the $c$ axis; (b) a $\left[\mathrm{ZnCl}_{4}\right]^{2-}$-based honeycomb-like framework; (c) a linear $i \mathrm{Q}[7]-\mathrm{Eu}^{3+}$-based coordination polymer surrounded by $\left[\mathrm{ZnCl}_{4}\right]^{2-}$ anions; (d) interactions between $i \mathrm{Q}[7]$ molecules and $\left[\mathrm{ZnCl}_{4}\right]^{2-}$ anions; (e) interactions between $i \mathrm{Q}[7]$ molecules and neighbouring linear polymers; (f) interactions between the $\mathrm{Eu}^{3+}$-linked $i \mathrm{Q}[7]$ molecules. 
Although compound 2 obtained from the $i \mathrm{Q}[7]-\mathrm{Yb}^{3+}-\mathrm{ZnCl}_{2}-\mathrm{HCl}$ system does not belong to the same isomorphous group as that of compound $\mathbf{1}$, the two compounds form similar supramolecular assemblies. Indeed, one can see such a supramolecular assembly constructed of $i \mathrm{Q}[7], \mathrm{Yb}^{3+}$, and $\left[\mathrm{ZnCl}_{4}\right]^{2-}$ anions (Figure $3 \mathrm{a}$ ). $\left[\mathrm{ZnCl}_{4}\right]^{2-}$ anions are attracted by the positively charged outer surface of the $i \mathrm{Q}[7]$ molecules and thus surround them, resulting in the formation of a $\left[\mathrm{ZnCl}_{4}\right]^{2-}$-based honeycomb-like framework (the honeycomb effect of the $\left[\mathrm{ZnCl}_{4}\right]^{2-}$ anion; Figure $3 \mathrm{~b}$ ). Meanwhile, the negatively charged environment around the $i \mathrm{Q}[7]$ molecules leads to a strong affinity for metal ions, such as $\mathrm{Yb}^{3+}$ cations. Thus, linear $i \mathrm{Q}[7] / \mathrm{Yb}^{3+}$-based supramolecular chains are formed, which reside in the channels of the $\left[\mathrm{ZnCl}_{4}\right]^{2-}$-based honeycomb (Figures 3a, 4c). Typical outer surface interactions of $i \mathrm{Q}[7] \mathrm{s}$ with $\left[\mathrm{ZnCl}_{4}\right]^{2-}$ anions comprise mainly dipole-dipole interactions between $\mathrm{Cl}$ from $\left[\mathrm{ZnCl}_{4}\right]^{2-}$ anions and methine or methylene units (black dashed lines) of the $i \mathrm{Q}[7]$ molecule (Figure $3 \mathrm{~d}$ ). The distances between the chloride and the methine or methylene carbons are in the range 3.288-3.423 $\AA$. The hydrogen bonding interactions can also be observed between the inverted portal carbonyl oxygen atoms of one $i \mathrm{Q}[7]$ molecule and the methylene groups on the outer surface of another between neighbouring $i \mathrm{Q}[7] / \mathrm{Yb}^{3+}$-based supramolecular chains (red dashed lines), with the hydrogen bonding distances in the range 2.932-3.129 $\AA$ (Figure 3e). Close inspection reveals that every two neighbouring $i \mathrm{Q}[7]$ molecules in a supramolecular chain are linked by one $\mathrm{Yb}^{3+}$ cation $(\mathrm{Yb} 1)$, which directly coordinates to two carbonyl oxygen atoms $(\mathrm{O} 1$, O2) from an $i \mathrm{Q}[7]$ molecule. Moreover, a coordinated water molecule $(\mathrm{O} 1 \mathrm{~W})$ resides 
at the portal of the $i \mathrm{Q}[7]$ molecule. The $\mathrm{Yb}^{3+}$ cation (Yb1) also interacts with the neighbouring $i \mathrm{Q}[7]$ molecule via hydrogen bonding of coordinated water molecules (O2W, O3W, O4W, O5W, O6W; Figure 3f). Thus, the Yb1 cation coordinates with eight oxygen atoms. The distances between $\mathrm{Yb}^{3+}$ and the portal carbonyl oxygen atoms are in the range 2.289-2.303 $\AA$, and the distances between carbonyl oxygen atoms and $\mathrm{O}_{\text {water }}$ are in the range $2.710-2.955 \AA$.

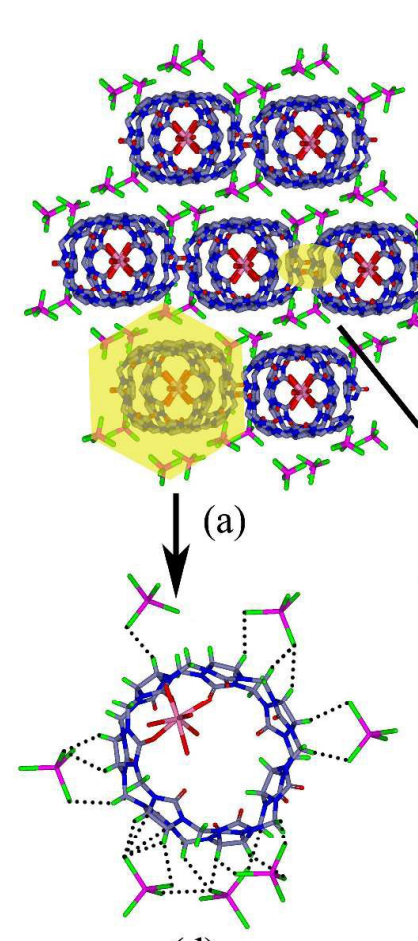

(d)

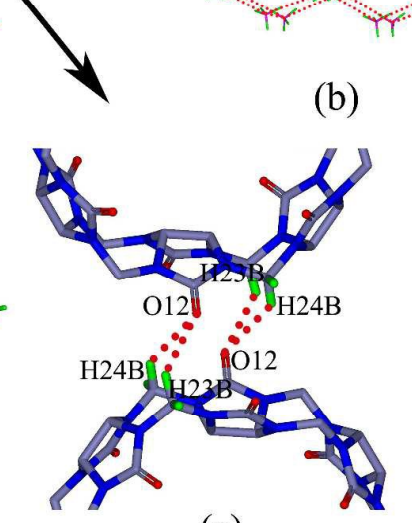

(e)

(b)
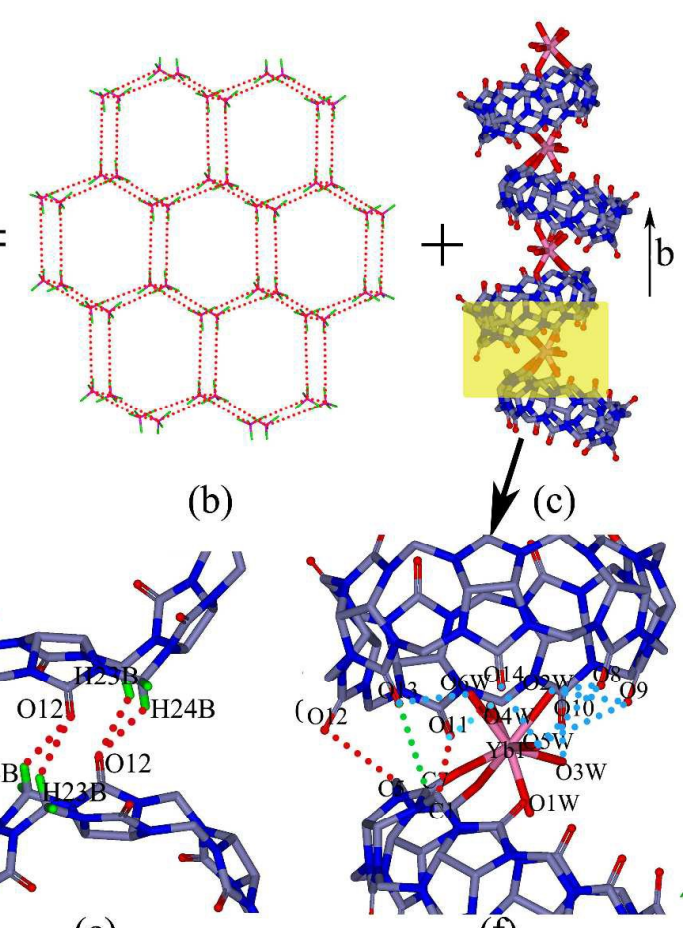

(f)

Fig. 3. X-ray crystal structure of compound 2: (a) overall view of the supramolecular assembly constructed of $i \mathrm{Q}[7]-\mathrm{Yb}^{3+}$ complexes and $\left[\mathrm{ZnCl}_{4}\right]^{2-}$ anions along the $b$ axis; (b) a $\left[\mathrm{ZnCl}_{4}\right]^{2-}$-based honeycomb-like framework; (c) a linear $i \mathrm{Q}[7]-\mathrm{Yb}^{3+}$-based coordination polymer surrounded by $\left[\mathrm{ZnCl}_{4}\right]^{2-}$ anions; (d) interactions between $i \mathrm{Q}[7]$ molecules and $\left[\mathrm{ZnCl}_{4}\right]^{2-}$ anions; (e) interactions between $i \mathrm{Q}[7]$ molecules and neighbouring linear polymers; (f) interactions between the $\mathrm{Yb}^{3+}$-linked $i \mathrm{Q}[7]$ molecules.

Our previous work ${ }^{[20]}$ revealed that normal Q[7] can form crystalline solids with a 
series of $\mathrm{Ln}^{3+}$ cations under similar experimental conditions, that is, with the aid of $\left[\mathrm{ZnCl}_{4}\right]^{2-}$ anions as a structure-directing agent. There was apparently no special selectivity of the normal Q[7] for the lanthanide cations, with almost all of the $\mathrm{Q}[7]-\mathrm{Ln}^{3+}-\left[\mathrm{ZnCl}_{4}\right]^{2-}$ systems yielding crystalline solids, although they could be classified into different isomorphous groups with increasing atomic number of the lanthanide. However, the inverted $i \mathrm{Q}[7]$ seems to display specific recognition properties for the lanthanide cations. Experiments showed that the $i \mathrm{Q}[7]-\mathrm{Ln}^{3+}-\left[\mathrm{ZnCl}_{4}\right]^{2-}$ systems with lighter $\mathrm{Ln}$, that is, $\mathrm{La}, \mathrm{Ce}, \mathrm{Pr}, \mathrm{Nd}$, and $\mathrm{Sm}$, gave no precipitate, whereas the remaining heavier Ln gave crystalline solids, which could be divided into two isomorphous groups (Table $\mathrm{S} 1$ in the $\mathrm{SI}$ ), for which $\mathrm{Eu}, \mathrm{Gd}$, and Lu constitute one group, and $\mathrm{Tb}, \mathrm{Dy}, \mathrm{Ho}, \mathrm{Er}, \mathrm{Tm}$, and $\mathrm{Yb}$ the other. X-ray powder diffraction patterns of two representative crystals of each of these compounds, and comparison with simulated patterns, revealed that the samples essentially consisted of pure crystalline phases (Figure 4).

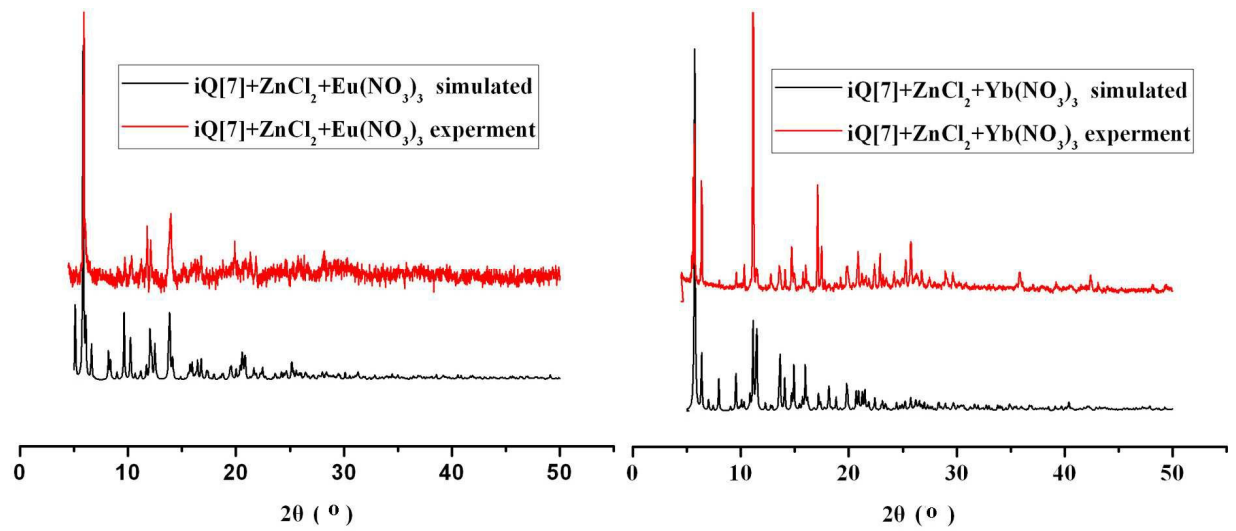

Fig. 4. X-ray powder diffraction patterns of compounds 1 and 2: as simulated (black) from single crystal XRD data, and as experimental (red). 
Sorption properties towards volatile materials: Moreover, both types of crystalline materials generally showed porous structural features, which could be utilized for selective sorption properties and can therefore be utilized for separation/purification applications. ${ }^{[22]}$ Figure 5 displays the sorption profiles for several volatile materials when using the $i \mathrm{Q}[7]$-based porous supramolecular assembly $\mathbf{1}$. A remarkable sorption capacity for methanol was observed at over $16 \mathrm{mmol}$ per gram, which is at least 20 times more than those of the other volatile materials screened at room temperature under atmospheric pressure. In contrast, powdered $i \mathrm{Q}[7]$ exhibited far less sorption capacities for methanol, in fact only one third of that of the $i \mathrm{Q}[7]$-based porous materials, although it displayed better sorption capacity for the remaining volatile materials. In particular, for acetonitrile, the sorption capacity was about 30 times more than that of the $i \mathrm{Q}[7]$-based porous materials (Figure $\mathrm{S} 1$ in the $\mathrm{SI}$ ).

Comparison of the sorption capacities of $i \mathrm{Q}[7]$-based porous material with those of $i \mathrm{Q}[7]$, under the same conditions, reveals that 1) the former show more obvious selectivity for polar volatile materials, especially methanol, due to the polar channels of the porous materials; 2) the channel sizes of the porous materials can influence the sorption capacities for polar volatile materials, for example, the significant difference between methanol and ethanol; 3) the latter shows no obvious selectivity for these volatile materials. These observations suggest that the $i \mathrm{Q}[7]$-based honeycomb-like framework play a pivotal role in the sorption processes. 


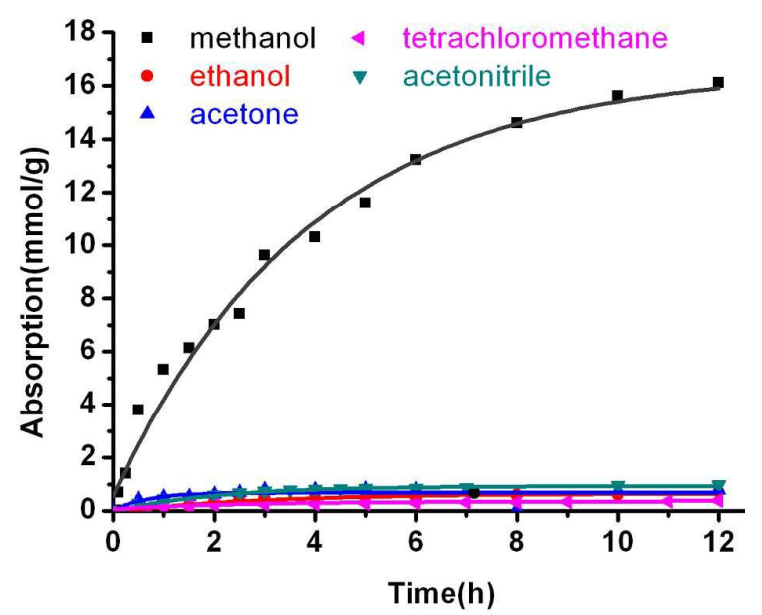

Fig. 5. Sorption profiles of volatile materials on the $i \mathrm{Q}[7]$-based porous

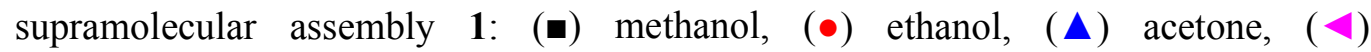
tetrachloromethane, $(\boldsymbol{\nabla})$ acetonitrile

\section{Conclusion}

In continuation of our previous work, ${ }^{[11]}$ we further selected $i \mathrm{Q}[7]$ as a ligand, and investigated its coordination behaviour and resulting supramolecular assemblies with $\mathrm{Ln}^{3+}$ cations in the presence of $\left[\mathrm{ZnCl}_{4}\right]^{2-}$ anions as structure-directing agents. Single-crystal X-ray diffraction analyses revealed that the honeycomb effect of $\left[\mathrm{ZnCl}_{4}\right]^{2-}$ anions results in the formation of linear coordination polymers of $\mathrm{Ln}^{3+}$ with $i \mathrm{Q}[7]$ molecules. The supramolecular assemblies constructed from the $1 \mathrm{D}$ $i \mathrm{Q}[7] / \mathrm{Ln}^{3+}$-based coordination polymers display porous structural features, the remarkable selective sorption properties of which have the potential to be used for separation/purification technologies. Moreover, unlike Q[7], which shows no special selectivity for the lanthanides, $i \mathrm{Q}[7]$ displays selectivity for lanthanides in the presence of $\left[\mathrm{ZnCl}_{4}\right]^{2-}$ anions. In particular, $i \mathrm{Q}[7]$ coordinates to heavy lanthanides, from $\mathrm{Gd}$ to $\mathrm{Lu}$, forming crystalline solids, whereas no solid products are formed with 
the light lanthanides, from La to Sm. Further investigations into these separation properties are ongoing in our laboratory.

\section{Experimental Section}

Synthesis. Chemicals such as lanthanide metal chlorides or nitrates were of reagent grade and were used without further purification. Elemental analyses were carried out on a EURO EA-3000 elemental analyzer. $i \mathrm{Q}[7]$ was synthesized and separated as described in our previous work. ${ }^{[9]}$

Preparation of compounds 1 and 2. Similar processes were used to prepare crystals of related compounds: $\mathrm{Ln}\left(\mathrm{NO}_{3}\right)_{3}(0.12 \mathrm{mmol})$ and $\mathrm{ZnCl}_{2}(12.18 \mathrm{mg}, 0.089$ mmol) were dissolved in $1.0 \mathrm{~mL}$ of $\mathrm{H}_{2} \mathrm{O}$ to prepare solution $\mathrm{A}$, $i \mathrm{Q}[7]$ (20 $\mathrm{mg}$, $0.015 \mathrm{mmol}$ ) was dissolved in $1.0 \mathrm{~mL} 3 \mathrm{M}$ of $\mathrm{HCl}$ to prepare solution $\mathrm{B}$, which was then added with stirring to solution A. X-ray quality crystals were obtained from the solution on prolonged standing ( $\leq 10$ days). The data for two representative compounds, namely $\left\{\mathrm{Eu}\left(\mathrm{H}_{2} \mathrm{O}\right)_{6}(i \mathrm{Q}[7]\} \cdot \mathrm{Cl} \cdot 2\left[\mathrm{ZnCl}_{4}\right] \cdot 2 \mathrm{H}_{3} \mathrm{O} \quad 10 \mathrm{H}_{2} \mathrm{O} \quad(\mathbf{1})\right.$, and $\left\{\mathrm{Yb}\left(\mathrm{H}_{2} \mathrm{O}\right)_{6} i \mathrm{Q}[7]\right\} 2\left[\mathrm{ZnCl}_{4}\right] \cdot \mathrm{Cl} \cdot 2 \mathrm{H}_{3} \mathrm{O} \cdot 10 \mathrm{H}_{2} \mathrm{O}$ (2) which were obtained from $\mathrm{Eu}\left(\mathrm{NO}_{3}\right)_{3}$ $(53.17 \mathrm{mg})$ and $\mathrm{Yb}\left(\mathrm{NO}_{3}\right)_{3}(53.54 \mathrm{mg})$ respectively, are presented herein. Anal. calcd. for compound 1, $\mathrm{C}_{42} \mathrm{H}_{100} \mathrm{~N}_{28} \mathrm{O}_{42} \mathrm{EuZn}_{2} \mathrm{Cl}_{9}(\%)$ : C, 22.21; H, 4.44; N, 17.27, found: $\mathrm{C}$, 22.14; $\mathrm{H}, 4.48 ; \mathrm{N}, 17.18$. Anal. calcd for compound $2, \mathrm{C}_{42} \mathrm{H}_{104} \mathrm{~N}_{28} \mathrm{O}_{44} \mathrm{YbZn}_{2} \mathrm{Cl}_{9}(\%)$ : $\mathrm{C}$, 21.67; H, 4.50; N, 16.84 , found: C, 21.58; H, 4.53; N, 16.73 .

X-ray crystallography. A suitable single crystal $\left(\sim 0.2 \times 0.2 \times 0.1 \mathrm{~mm}^{3}\right)$ was embedded in paraffin oil. The resulting specimen was mounted on a Bruker SMART 
Apex II CCD diffractometer equipped with a graphite-monochromated Mo- $K_{\alpha}$ radiation source $\left(\lambda=0.71073 \AA, \mu=0.828 \mathrm{~mm}^{-1}\right)$, which was operated in the $\omega$-scan mode at room temperature. Data were corrected for Lorentz and polarization effects by using the SAINT program, and semi-empirical absorption corrections based on equivalent reflections were also applied by using the SADABS program. The structure was elucidated through direct methods and then refined by the full-matrix least-squares method on $F^{2}$ using the SHELXS-97 and SHELXL-97 program packages, respectively. ${ }^{[23,24]}$ All non-hydrogen atoms were refined anisotropically. Carbon-bound hydrogen atoms were introduced at calculated positions, and were treated as riding atoms with an isotropic displacement parameter equal to 1.2 times that of the parent atom. Most of the water molecules in the compounds were omitted by using the SQUEEZE option of the PLATON program. There were 22 and 24 squeezed water molecules for compounds $\mathbf{1}$ and 2, respectively. Analytical expressions for neutral-atom scattering factors were employed, and anomalous dispersion corrections were incorporated. Details of the crystal parameters, data collection conditions, and refinement parameters for the three compounds are summarized in Table 1. In addition, crystallographic data for the reported structures have been deposited at the Cambridge Crystallographic Data Centre as supplementary publication numbers CCDC 1025388 (1) and 1025389 (2). These data may be obtained free of charge via http://www.ccdc.cam.ac.uk/data_request/cif, by emailing data_request@ccdc.cam.ac.uk, or by contacting The Cambridge Crystallographic Data Centre, 12, Union Road, Cambridge CB2 1EZ, UK (fax: +44 1223 336033). 


\section{$\langle$ Table 1〉}

\section{Acknowledgements}

We acknowledge the support of National Natural Science Foundation of China (No. 21561007, 21272045). CR thanks the EPSRC for the award of a travel grant.

\section{References}

[1] L. Isaacs, S. K. Park, S. M. Liu, Y. H. Ko, N. Selvapalam, Y. Kim, H. Kim, P. Y. Zavalij, G. H. Kim, H. S. Lee, K. Kim, J. Am. Chem. Soc. 2005, 127, 18000-18001.

[2] S. M. Liu, K. Kim, L. Isaacs, J. Org. Chem. 2007, 72, 6840-6847.

[3] L. D. Isaacs, S. M. Liu, K. Kim, S. K. Park, Y. H. Ko, H. Kim, Y. Kim, N. Selvapalam, Introverted cucurbituril compounds and their preparation, crystal structure and binding properties. PCT Int. Appl. 2007, 48.

[4] R. V. Pinjari, S. P. Gejji, J. Phys. Chem. A, 2009, 113, 1368-1376.

[5] I. A. Raja, V. V. Gobre, R. V. Pinjari, S. P. Gejji, J. Mol. Model. 2014, 20, 1-6.

[6] K. I. Assaf, W. M. Nau, Chem. Soc. Rev., 2015, 44, 394-418.

[7] X. L. Ni, X. Xiao, H. Cong, Q. J. Zhu, S. F. Xue, Z. Tao, 2014, Acc. Chem. Res. 47, 1386-1395.

[8] D. Q. Zhang, Y. Q. Zhang, S. F. Xue, Z. Tao, X. Xiao, Q. J. Zhu, Polyhedron 2015, 99, 147-155.

[9] Q. Li, Y. Q. Zhang, Q. J. Zhu, S. F. Xue, Z. Tao, X. Xiao, Chem. Asian J. 2015, 10, 
1159-1164.

[10] Y. Zhao, L. L. Liang, K. Chen, T. Zhang, X. Xiao, Y. Q. Zhang, Z. Tao, S. F. Xue, Q. J. Zhu, CrystEngComm. 2013, 15, 7987-7998.

[11] L. L. Liang, Y. Zhao, Y. Q. Zhang, Z. Tao, S. F. Xue, Q. J. Zhu, J. X. Liu, CrystEngComm. 2013, 15, 3943-3950.

[12] L. L. Liang, X. L. Ni, Y. Zhao, K. Chen, X. Xiao, Y. Q. Zhang, C. Redshaw, Q. J. Zhu, S. F. Xue, Z. Tao, Inorg. Chem. 2013, 52, 1909-1915.

[13] I. Hwang, W. S. Jeon, H. J. Kim, D. Kim, H. Kim, N. Selvapalam, N. Fujita, S. Shinkai, K. Kim, Angew. Chem., Int. Ed. 2007, 46, 210-213.

[14] S. Lim, H. Kim, N. Selvapalam, K. J. Kim, S. J. Cho, G. Seo, K. Kim, Angew. Chem., Int. Ed. 2008, 47, 3352-3335.

[15] H. Kim, Y. Kim, M. Yoon, S. Lim, S. M. Park, G. Seo, K. Kim, J. Am. Chem. Soc. 2010, 132, 12200-12202.

[16] M. Yoon, K. Suh, H. Kim, Y. Kim, N. Selvapalam, K. Kim, Angew. Chem., Int. Ed. 2011, 50, 7870-7873.

[17] W. X. Zhao, C. Z. Wang, Y. Q. Zhang, S. F. Xue, Q. J. Zhu, Z. Tao, New J. Chem. 2015, 39, 2433-2436.

[18] C. Z. Wang, W. X. Zhao, Y. Q. Zhang, S. F. Xue, Q. J. Zhu, Z. Tao, RSC Adv. 2015, 5, 17354-17357.

[19] N. N. Ji, X. J. Cheng, Y. Zhao, L. L. Liang, K. Chen, X. Xiao, Y. Q. Zhang, Q. J. Zhu, S. F. Xue, Z. Tao, Eur. J. Inorg. Chem. 2014, 1435-1438.

[20] X. L. Ni, X. Xiao, H. Cong, L. L. Liang, K. Chen, X. J. Cheng, N. N. Ji, Q. J. 
Zhu, S. F. Xue, Z, Tao, Chem. Soc. Rev. 2013, 42, 9480-9508.

[21] X. L. Ni, S. F. Xue, Z. Tao, Q. J. Zhu, L. F. Lindoy, G. Wei, Coord. Chem. Rev. 2015, 287, 89-113.

[22] Y. Zhao, L. L. Liang, K. Chen, N. N. Ji, X. J. Cheng, X. Xiao, Y. Q. Zhang, S. F. Xue, Q. J. Zhu, N. Dong, Z, Tao, Dalton Trans. 2014, 43, 929-932.

[23] G. M. Sheldrick, Acta Crystallogr. Sect. A, 2008, 64, 112-122.

[24] G. M. Sheldrick, SHELXL-97 Program for the Solution and Refinement of Crystal structures, University of Göttingen, Germany, 1997. 
Table 1. Crystal data and structure-refinement details for compounds $\mathbf{1}$ and $\mathbf{2}$

\begin{tabular}{|c|c|c|}
\hline Compound & 1 & 2 \\
\hline Chemical formula & $\begin{array}{c}\mathrm{C} 42 \mathrm{H} 42 \mathrm{Eu} \mathrm{N} 28 \mathrm{O} 20 \\
2\left(\mathrm{ZnCl}_{4}\right), \mathrm{Cl} \\
2\left(\mathrm{H}_{3} \mathrm{O}\right) \cdot 10\left(\mathrm{H}_{2} \mathrm{O}\right)\end{array}$ & $\begin{array}{c}\mathrm{C} 42 \mathrm{H} 42 \mathrm{~N} 28 \mathrm{O} 20 \mathrm{Yb}, \\
2\left(\mathrm{ZnCl}_{4}\right), \mathrm{Cl} .2\left(\mathrm{H}_{3} \mathrm{O}\right) . \\
10\left(\mathrm{H}_{2} \mathrm{O}\right)\end{array}$ \\
\hline Formula weight & 2078.78 & 2099.86 \\
\hline Crystal system & Monoclinic & Monoclinic \\
\hline Space group & $P 2_{l} / c$ & $P 2_{l} / n$ \\
\hline$a, \AA$ & $17.837(5)$ & $17.2855(9)$ \\
\hline$b, \AA$ & $26.629(7)$ & $18.4861(9)$ \\
\hline$c, \AA$ & $18.949(5)$ & $27.8919(15)$ \\
\hline$\alpha, \operatorname{deg}$ & 90.00 & 90.00 \\
\hline$\beta, \operatorname{deg}$ & $104.892(9)$ & $96.995(2)$ \\
\hline$\gamma, \operatorname{deg}$ & 90.00 & 90.00 \\
\hline$V, \AA^{3}$ & $8698(4)$ & $8846.3(8)$ \\
\hline Z & 4 & 4 \\
\hline Dcalcd, $\mathrm{g} \mathrm{cm}^{-3}$ & 1.421 & 1.413 \\
\hline $\mathrm{T}, \mathrm{K}$ & $223(2)$ & $223(2)$ \\
\hline$\mu, \mathrm{mm}^{-1}$ & 1.606 & 1.928 \\
\hline Unique reflns & 20388 & 20261 \\
\hline Obsd reflns & 12619 & 14428 \\
\hline Params & 935 & 937 \\
\hline Rint & 0.0676 & 0.0494 \\
\hline $\mathrm{R}[\mathrm{I}>2 \sigma(\mathrm{I})]^{\mathrm{a}}$ & 0.0689 & 0.0564 \\
\hline $\mathrm{wR}[\mathrm{I}>2 \sigma(\mathrm{I})]^{\mathrm{b}}$ & 0.2047 & 0.1729 \\
\hline $\mathrm{R}$ (all data) & 0.1066 & 0.0811 \\
\hline wR(all data) & 0.2331 & 0.1915 \\
\hline GOF on $\mathrm{F} 2$ & 1.070 & 1.045 \\
\hline
\end{tabular}

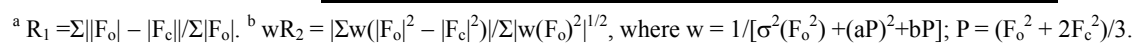

